\title{
Case report: New clinical clue of hyper-endogenous heparinization provides an imperative guideline for Treatment of Postpartum Hemorrhage with DIC via TEG guides and protamine intervention
}

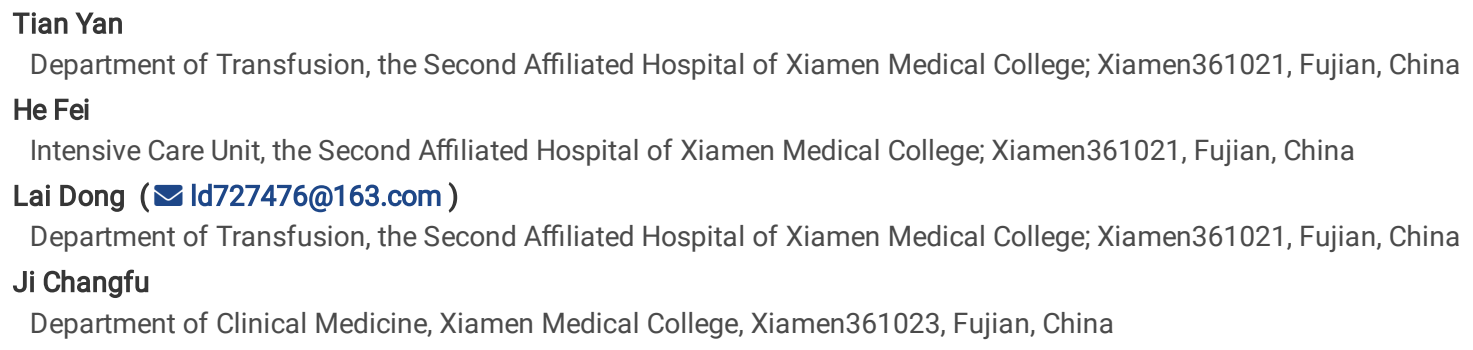

Research

Keywords: Postpartum Hemorrhage, Hyper-heparinization, Thromboelastography, Protamine, Case report

Posted Date: June 29th, 2020

DOI: https://doi.org/10.21203/rs.3.rs-35288/v1

License: (c) (1) This work is licensed under a Creative Commons Attribution 4.0 International License. Read Full License 


\section{Abstract}

Background

Postpartum hemorrhage (PPH) is a leading cause of maternal mortality and severe maternal morbidity worldwide and involves disseminated intravascular coagulation (DIC) secondary to cause massive blood loss. The coagulation abnormality in response to severe trauma or infection is a latent cause that may aggravate $\mathrm{PPH}$.

\section{Case presentation}

A 26-year-old puerpera with 39 weeks of menolipsis case lacks amniotic fluid and uterus infection was examined. During the cesarean section, the patient presented fever and massive hemorrhage that she became the DIC and shock. The low coagulation of this PPH patient was diagnosed by Thromboelastography (TEG) guiding with heparinase (type I). The patient appeared a critical condition admitted in emergency room. According the continuous detection via TEG guides assay, she was observed in coagulopathy and hyper-heparinization. And subsequently the protamine correction for the patient's coagulation abnormality, the patient who became a stable condition after 4 hours of urgent treatment.

\section{Conclusion}

TEG-guided determination of endogenous heparin and subsequent infusion of protamine effectively reversed the syndrome of PPH with DIC. This is the first case report that infection and bleeding might be major causes of hyper-endogenous heparinization without exogenous heparin intervention. The hyperendogenous heparinization is clinically taken into consideration for the syndrome of PPH with low coagulation.

\section{Plain English Summary}

Postpartum hemorrhage (PPH) is a leading cause of maternal mortality and severe maternal morbidity worldwide and involves disseminated intravascular coagulation (DIC) secondary to cause massive blood loss. The coagulation abnormality in response to severe trauma, infection or bleeding with infection hinders treatment strategy that may aggravate $\mathrm{PPH}$.

A 26-year-old puerpera with 39 weeks of menolipsis case lacks amniotic fluid and uterus infection was examined. During the cesarean section, the patient occurred fever and massive hemorrhage that she became the DIC and shock. The abnormal coagulation of this PPH patient was diagnosed by Thromboelastography (TEG) guiding with heparinase (type I) and appeared a critical condition admitted in emergency room. According TEG guides assay, she was observed in coagulopathy and hyper-heparinization and the protamine invention corrected her coagulation abnormality, she who became a stable condition after 4 hours of urgent treatment.

Notably, this phenomenon of endogenous heparinization needs to have an insight into refocusing the interference of catheter heparin sealing which heparin leaks into the vein to cause the obscure outcome such as endogenous plus exogenous heparin or exogenous heparin alone problem. This confusion has to be paid more attention through Medicare via nurse during intravenous drip.

In conclusion, TEG-guided determination of endogenous heparin and subsequent infusion of protamine effectively reversed the syndrome of PPH with DIC. This is the first case report that infection and bleeding might be major causes of hyper-endogenous heparinization without exogenous heparin intervention. The hyper-endogenous heparinization is clinically taken into reassessment for low coagulation syndrome of PPH.

\section{Background}

Postpartum hemorrhage (PPH) is a leading cause of maternal mortality and severe maternal morbidity worldwide and strategies to prevent and treat PPH vary among international authorities (Higgins et al., 2019). Abnormal coagulation is the main factor leading to PPH, and effective control of coagulation in patients with PPH is crucial. Currently, the focus on abnormal coagulation in PPH mainly involves in DIC secondary to massive blood loss (Tamura et al., 2017). However, there is rare research on the endogenous heparinization causing coagulation abnormalities or even DIC that may aggravate the severity of $\mathrm{PPH}$. Thromboelastography (TEG) is recommended in the relevant tissue guidelines for the detection of PPH. Notably, we found a high endogenous heparinization of PPH patient complicated with infection and DIC through the detection of TEG cup with heparinase or heparin.

\section{Case Presentation}

The puerpera had fully understood and signed a written informed consent to publish the case report. 26-year-old puerpera with 39 weeks of menolipsis was hospitalized on November 14, 2018 lack of amniotic fluid with unknown reasons. The color Doppler ultrasound check indicated that all tests were normal except only $64 \mathrm{~mm}$ of amniotic fluid which might be caused by the hypofunction of the placenta. On November 15, an intravenous drip of oxytocin was put on the puerpera for odinapoeia until 5:15 pm. At 8:50 pm, the patient had a fever of $39^{\circ} \mathrm{C}$ with chilly and shivering. The result of blood test showed the rise of the leukocyte count, neutrophil ratio, and C-reactive protein. The fetal membrane was ruptured, the amniotic fluid was degree 1 turbid, fetal tachycardia, and irregular contractions, which indicates intrauterine infection.

At 9:50 pm, November 15, a caesarean section was carried out to terminate pregnancy while amniotic fluid of the puerpera was 3 degree turbid. The puerpera gave a baby boy birth at 10:11 pm and began vomiting at 10:55 pm. Her blood pressure lowered to $82 / 45 \mathrm{mmHg}$, heart rate reached $131 / \mathrm{min}$, and capillary hemorrhage occurred in many places of omentum majus. The nasal cavity spontaneously began to bleed lasting for 7 minutes, and the patient's 
blood did not coagulate and suspected DIC. During the hemorrhage of the greater omentum suture, the patient had obvious infiltration of abdominal wall muscles and subcutaneous fat, and the DIC score reached 10 points (The primary disease 2 points; PLT 50×109/L, 1 point; PT 21.1s, 2 points; FDP significantly increased by 4 points; Fib $<1 \mathrm{~g} / \mathrm{L}, 1$ point). Based on the Dominant DIC International Standard of Thrombus and Hemostasis Committee (ISTH Standard), the DIC score was above 5, indicating that the patient was in severe hypocoagulation. The PPH with DIC patient became a critical moment and needed to be urgently treated. Therefore, thromboelastography (TEG) was employed to measure the coagulation state after sampling. TEG assay showed the $R$ value was extended and the line sustained over $30 \mathrm{~min}$. At 11:18 pm based on the laboratory results, the patient was given a cryoprecipitate of $10 \mathrm{U}$ and RBC $4 \mathrm{U}$, adjunctive use of anti-fibrinolytic and anti-infective drugs, and unfortunately the patient's kept bleeding.

Combined with APTT extension, TT and R value extension, TEG heparinase contrast test (hmTEG) was performed to test this sample again. The results revealed that the coagulation state was significantly improved after the neutralization of heparinase, and TEG results (R 8.5 min, Angle 22.9 , MA 34.7 mm) were also confirmed. This indicates that the patient had severe heparinization while this could be a self-production of heparin substance not derived from any heparin-related medication. This state was confirmed by surgical team that no heparin closure was performed. Immediately, the patient's coagulation function was significantly improved (R $12.5 \mathrm{~min}$, Angle $20.3^{\circ}$, MA $30.1 \mathrm{~mm}$ ) after $40 \mathrm{mg}$ of protamine injection, designating that heparin was offset.

However, the result of the coagulation also revealed a lack of fibrinogen and platelet. The platelets were not available, $10 \mathrm{U}$ of cryoprecipitate and $4 \mathrm{U}$ of RBC were slightly promoted the coagulation. At 00:54 am, November 16, the patient's condition worsened again as evidenced by $200 \mathrm{~mL}$ of blood exuding from the wound without clot. The DIC score was still above 5. Unexpectedly, the results showed that the R value was extended and the line sustained for 30 min. and the antagonism of heparinase was improved ( $8 \mathrm{~min}$, Angle $23.6^{\circ}$, MA $34 \mathrm{~mm}$ ). This result turned out to have the abnormality of coagulation again, and heparinase counteraction was enhanced. After injection of $40 \mathrm{mg}$ protamine again, the coagulation function had pronounced improvement (R 8.6 min, Angle $21.6^{\circ}$, MA $30 \mathrm{~mm}$ ). The DIC score gradually dropped below $5.24 \mathrm{U}$ of cryoprecipitate, 2 dosis curativa of platelets, and $4 \mathrm{~g}$ of fibrin preparation were transfused. The patient's coagulation function basically returned to normal at 02:43 am, November 16, 2018. The patient was sent to ICU for further care and treatment at 03:50 am. We also examined two indicators of vascular endothelial cell injury: thromboregulatory protein (TM 3.8-13.3 TU/mL) and tissue plasminogen activator inhibitor 1 complex (tPAl-C<10.5 ng/mL). At 09:10 pm, November15, 2018, TM was 11.8 TU/Ml and tPAl-C was 14.7 ng/mL. At 11:18 pm, November15, 2018, TM was 14.9 TU/mL and tPAl-C was $27.5 \mathrm{ng} / \mathrm{mL}$. At 00:54 am, November16, 2018, TM was 23.6 TU/mL and tPAl-C was 32.3 $\mathrm{ng} / \mathrm{mL}$. At 11:18 pm, November 15, 2018, ATIII (81.5\%-121.3\%) level was 22.56\%. At 01:27 am, November16, ATIII level was 39.21\%, but the level was elevated $58.23 \%$ at $04: 41$ am, November16.

During the treatment, the patient presented with the symptoms of double lung respiratory sound and wet rales. Bedside chest X-ray revealed double lung patch shadows and pleural effusion, the hemogram of the patient exhibited persistent symptoms of infection. Blood cultured on November 15 , the result showed Escherichia infection of patient. After anti-infection treatment, the patient gradually became stable condition and discharged from the hospital on November 28, 2018.

\section{Discussion}

The puerpera appeared multiple site bleeding confirmed DIC according ISTH Standard, the cause of her bleeding was further found the release of endogenous heparin substances excluded exogenous heparin interference (within 5 hours of rescue, the operation group confirmed that no heparin was used to seal the catheter). Then we immediately gave her a protamine intervention, the corrected effect was very significant and the rescue time of emergency crisis was shortened to only 5 hours. The coagulation disorder of the patient was corrected no recurrent bleeding (Fig. 1). Normally, endogenous heparinization is rare in PPH patients. Recently, the endogenous heparinization of PPH patient with DIC was reported by Wang et al., (2019). Herein both cases (including our case) have demonstrated the importance of recognition of high heparinization in PPH. Nevertheless, the effect of heparin in that case was identified within 24 hours and the syndrome was relieved at 72 hours (Wang et al., 2019). Notably, this phenomenon of endogenous heparinization needs to get an insight into concerning the interference of catheter heparin sealing which heparin leaks into the vein to cause the obscure outcome such as endogenous plus exogenous heparin or exogenous heparin alone problem. This confusion has to be further verified through Medicare via nurse during intravenous drip. More obviously, the identification of endogenous heparinization and targeted treatment were shortly and effectively obtained (within 5 hours) in our case, confirming this hyper-endogenous heparinization to be more reliable and is worth considering in management of PHH with DIC patient.

The phenomenon of endogenous heparinization of the patient appears recurrently twice during the process of rescue, and there are some other evidences which can confirm the phenomenon of endogenous heparinization for our patient. Firstly, R time was greatly reduced and Angle was correspondingly increased because of heparinase neutralization. On the other hand, the combination of heparin and antithrombin III (ATIII) plays an anticoagulant role in this case. ATIII levels were decreased as maternal levels of endogenous heparin increased. Moreover, the diagnosis of this patient was associated with intrauterine infection before surgery (2018-11-15 21:32, Table 1). When compared with Wang et al., (2019) report without infection, our report shows that the occurrence of endogenous heparinization in pregnant women is obviously accompanied by the infection. In this process has been accompanied by a severe infection in patients with the phenomenon, the 2018-11-15 is also found in the blood culture of E. coli infection, caused by infection with inflammation and ischemia reperfusion of great damage to vascular endothelial cells, and reflect the index of TM in patients with vascular endothelial injury and tPAl-C levels are shown as standard of heparinization aggravating gradually rising phenomenon. At 00:54 am, November 16, 2018, TM was 23.6 TU/ml and tPAl-C was $32.3 \mathrm{ng} / \mathrm{mL}$. The highest levels of TM and tPAI-C are observed and the heparinization level is very serious at this time. This indicates that the injury of vascular endothelial cells causes the release of endogenous heparin-like substances, which is consistent with the previous report (Schwameis et al., 2015). Furthermore, the mechanistic actions of acute traumatic coagulopathy have been demonstrated the activation of protein C, endothelial glycocalyx disruption, depletion of fibrinogen, and platelet dysfunction (Schwameis et al., 2015). These multifactorial processes lead to hypoperfusion, decreased clot strength, autoheparinization, and hyperfibrinolysis (Maegele, 2014; Simmons and Powell, 2016). Interestingly, the autoheparinization of coagulation abnormality might be ascribed to the hyper-endogenous heparinization shown in our PPH case.

Page $3 / 6$ 
Injury of vascular endothelial cells is a process, and the release of endogenous heparin-like substances will continue. After a brief remission of DIC and coagulation disorders by protamine and blood products, there is a risk that the coagulation disorders will continue to worsen due to the continued release of endogenous heparin-like substances. Therefore, while monitoring the coagulation function in the rescue of critically ill parturient women, it is crucial to accurately judge whether the patients have the release of endogenous heparin-like substances and timely intervention. From the experience of this rescue, we believe that infection and ischemia reperfusion may be the main reasons for the release of endogenous heparin-like substances in this patient. TEG increases its impact on coagulation assessment and helps guide resuscitation and blood product transfusion (Espinosa and Ekeland, 2017; Sumislawski et al., 2019). It was very effective in identifying the heparin effect. The timely use of protamine has a significant effect on reversing the progress and occurrence of DIC in this parturient, and has a reference significance for the treatment of PPH patients in the future. In conclusion: Vascular endothelial injury secondary to infection and blood loss leads to the release of endogenous heparin-like substances in parturient women. The massive release of heparin-like substances promotes the development of coagulation disorders and DIC. The intervention of protamine effectively reverses the deterioration of DIC.

\section{Conclusion}

The incidence of self-heparin on both coagulation and infection condition was found to persist during the treatment of this case. TEG-guided determination of endogenous heparin and subsequent infusion of protamine effectively reversed the syndrome of PPH puerpera with DIC. This is the first case report that infection and bleeding might be major causes of hyper-endogenous heparinization without exogenous heparin intervention. The hyper-endogenous heparinization is clinically taken into reconsideration for the syndrome of $\mathrm{PPH}$ with coagulation abnormality.

\section{Abbreviations}

ATIII: Antithrombin III; DIC: disseminated intravascular coagulation; HS: heparan sulfate; PPH: Postpartum hemorrhage; TEG: thromboelastography

\section{Declarations}

\section{Ethics approval and consent to participate}

The patient signed a written consent allowing the case to be published

\section{Consent for publication}

Written informed consent was obtained from study participants for publication

Availability of Data and Materials: Not applicable

\section{Competing interests}

The authors declare no conflicting interests.

\section{Funding}

This work was supported by Health and family planning of Fujian provincial commission for youth research project (2018-2-70)

\section{Authors' contributions}

TY. and HF. participated in research design, data analysis, and manuscript preparation. HF. and TY. carried out laboratory tests and collected experimental data. LD. designed the study and critically reviewed the manuscript. All authors reviewed and approved the final version of manuscript.

\section{Acknowledgements}

We sincerely thank Professor Ching-Feng Weng for his critical reviewing this manuscript. Specially thanks to John Koester for his English editing.

\section{References}

Espinosa, A. \& Ekeland, M. S. (2017). [Thromboelastography - useful in cases of bleeding?]. Tidsskr Nor Laegeforen, 137(5), 367-370. doi:10.4045/tidsskr.16.0208

Higgins, N., Patel, S. K. \& Toledo, P. (2019). Postpartum hemorrhage revisited: new challenges and solutions. Curr Opin Anaesthesiol, 32(3), $278-284$. doi:10.1097/AC0.0000000000000717

Madhumita, Premkumar, Bihari, Chhagan \& Saxena, Priyanka. (2019). Heparin-like Effect Associated With Risk of Bleeding, Sepsis, and Death in Patients With Severe Alcohol-associated Hepatitis. doi:10.1016/j.cgh.2019.04.057

Maegele, M. (2014). The coagulopathy of trauma. Eur J Trauma Emerg Surg, 4O(2), 113-126. doi:10.1007/s00068-014-0389-4 
Schwameis, M., Schober, A., Schorgenhofer, C., Sperr, W. R., Schochl, H., Janata-Schwatczek, K., Kurkciyan, E. I., Sterz, F. \& Jilma, B. (2015). Asphyxia by Drowning Induces Massive Bleeding Due To Hyperfibrinolytic Disseminated Intravascular Coagulation. Crit Care Med, 43(11), $2394-2402$. doi:10.1097/CCM.0000000000001273

Simmons, J. W. \& Powell, M. F. (2016). Acute traumatic coagulopathy: pathophysiology and resuscitation. Br J Anaesth, 117 (suppl 3), iii31-iii43. doi:10.1093/bja/aew328

Sumislawski, J. J., Christie, S. A., Kornblith, L. Z., Stettler, G. R., Nunns, G. R., Moore, H. B., Moore, E. E., Silliman, C. C., Sauaia, A., Callcut, R. A. \& Cohen, M. J. (2019). Discrepancies between conventional and viscoelastic assays in identifying trauma-induced coagulopathy. Am J Surg, $217(6), 1037-1041$.

doi:10.1016/j. amjsurg.2019.01.014

Tamura, N., Farhana, M., Oda, T., Itoh, H. \& Kanayama, N. (2017). Amniotic fluid embolism: Pathophysiology from the perspective of pathology. J Obstet Gynaecol Res, 43(4), 627-632. doi:10.1111/jog.13284.

Wang, S., Qi, C., Liu, Zh, Xu, T. \& Yao, Cy. (2019) Endogenous Heparin-Like Substances May Cause Coagulopathy in a Patient with Severe Postpartum Hemorrhage. Transfus Med Hemother. 2019. doi: 10.1159/000504610.

\section{Table}

Table 1. History of medical examinations from the puerpera during critical period.

\begin{tabular}{|c|c|c|c|c|c|c|c|c|c|c|c|c|}
\hline \multirow{2}{*}{$\begin{array}{l}\text { Date } \\
\text { Acquisition time }\end{array}$} & & \multicolumn{5}{|c|}{ 2018-11-15 } & \multicolumn{6}{|c|}{ 2018-11-16 } \\
\hline & & 7:00 & 9:10 & $11: 18$ & & 11:40pm & $0: 54$ an & 1: & 7am & $1: 27$ & $2: 43$ & $4: 41$ \\
\hline \multirow[t]{3}{*}{$\begin{array}{l}\text { Routine } \\
\text { blood }\end{array}$} & $\begin{array}{l}\text { WBC } \\
\left(\times 10^{9} / \text { L】 }\right.\end{array}$ & 7.80 & 14.74 & 10.95 & & & 10.20 & & & 9.35 & 19.62 & 20.70 \\
\hline & $\begin{array}{l}\mathrm{HGB} \\
(\mathrm{g} / \mathrm{LV}\end{array}$ & 125 & 146 & 92 & & & 77 & & & 90 & 95 & 92 \\
\hline & 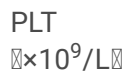 & 183 & 113 & 77 & & & 50 & & & 37 & 74 & 71 \\
\hline \multirow[t]{7}{*}{ Coagulation Function } & APTT (s) & & 41.0 & 106.1 & & & 71 & & & 48.5 & 40.1 & 44.3 \\
\hline & PT (s) & & 13.4 & 21.1 & & & 19.8 & & & 15.4 & 14.8 & 13.3 \\
\hline & $\mathrm{FiB}(\mathrm{g} / \mathrm{L} \rrbracket$ & & 2.43 & 0.52 & & & 0.82 & & & 2.63 & 3.00 & 2.93 \\
\hline & $\mathrm{TT}(\mathrm{s})$ & & 21.3 & 28.7 & & & 25.2 & & & 15.9 & 15.2 & 18.8 \\
\hline & $\begin{array}{l}\text { DIC } \\
\text { score }\end{array}$ & & 4 & 11 & & & 10 & & & 6 & 5 & \\
\hline & $\begin{array}{l}\text { FDP } \\
(\mu \mathrm{g} / \mathrm{mL})\end{array}$ & & 33.4 & 116.2 & & & 98.6 & & & 36 & 32 & \\
\hline & AT囚\% & & & 22.56 & & & 39.21 & & & & & 58.23 \\
\hline \multirow[t]{4}{*}{ TEG } & & CK & CK & CK & $\mathrm{CKH}$ & Protamineintervention & CK & $\mathrm{CKH}$ & $\begin{array}{l}\text { Protamine } \\
\text { intervention }\end{array}$ & CK & CK & $\mathrm{CK}$ \\
\hline & $\mathrm{R}(\min )$ & 7.8 & 15.1 & 70.2 & 8.5 & 12.5 & 48.2 & 8.0 & 8.6 & 9.0 & 10.3 & 11.8 \\
\hline & Angle & 35.7 & 20.3 & & 22.9 & 20.3 & & 23.6 & 21.6 & 57.1 & 52.6 & 38.8 \\
\hline & $\begin{array}{l}\text { MA } \\
(\mathrm{mm})\end{array}$ & 48.7 & 30.1 & & 34.7 & 30.1 & & 34.0 & 30.0 & 53.0 & 54.4 & 62.4 \\
\hline \multirow[t]{4}{*}{ Inflammatory biomarkers } & $\begin{array}{l}\mathrm{PCT} \\
(\mu \mathrm{g} / \mathrm{L})\end{array}$ & & 26.09 & & & & & & & & & 150.0 \\
\hline & $\begin{array}{l}\text { CRP } \\
\text { (mg/L) }\end{array}$ & & 0.08 & & & & & & & & & 58.36 \\
\hline & $\begin{array}{l}\mathrm{TM} \\
(\mathrm{TU} / \mathrm{mL})\end{array}$ & & 11.8 & 14.9 & & & 23.6 & & & & & \\
\hline & $\begin{array}{l}\text { tPAl-C } \\
(\mathrm{ng} / \mathrm{mL})\end{array}$ & & 14.7 & 27.5 & & & 32.3 & & & & & \\
\hline
\end{tabular}

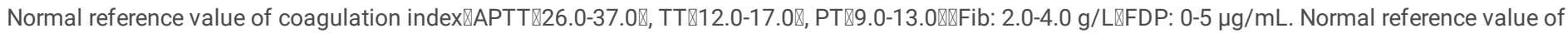

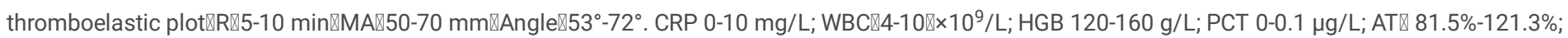




\section{Figures}

\section{Coagulation index}

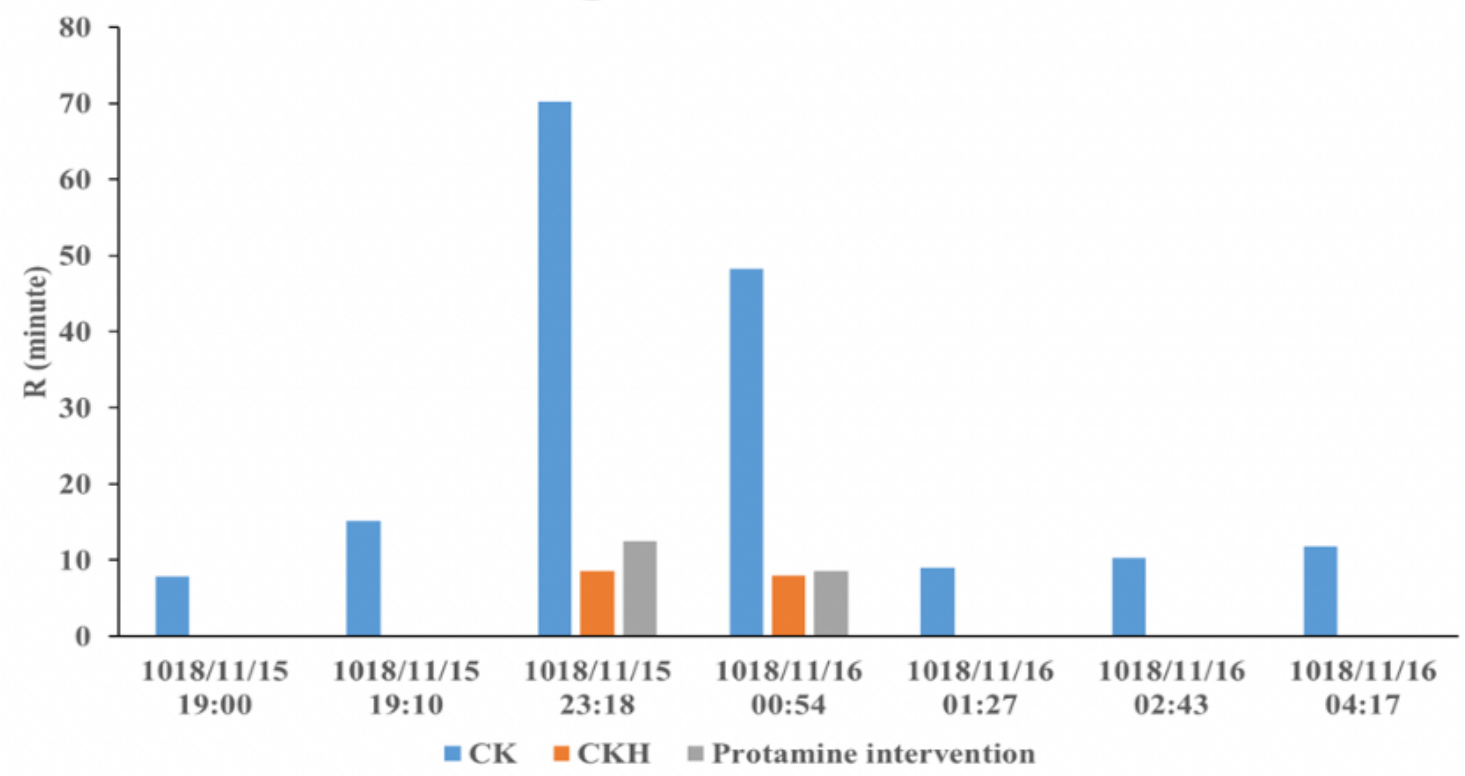

Figure 1

The profile of coagulation in PPH with DIC patient using TEG measurement. CK: heparin; $\mathrm{CKH}$ : heparinase 